\title{
Editorial: Mindfulness and Eating Behavior
}

\author{
Michail Mantzios* \\ Department of Psychology, Birmingham City University, Birmingham, United Kingdom
}

Keywords: mindfulness, mindful eating, obesity, eating behavior, self-regulation

\section{Editorial on the Research Topic}

\section{Mindfulness and Eating Behavior}

Research associating mindfulness and eating behavior has a short history that starts with the first publication almost two decades ago (Kristeller and Hallett, 1999). Since then, a consistent body of research developed our understanding for the treatment of eating disorders (e.g., Kristeller and Wolever, 2010) and obesity (e.g., Mantzios and Wilson, 2015), and a plethora of methods achieving the end goal of self- and weight- regulation have been proposed and investigated (e.g., Tapper, 2017). From brief mindful eating interventions (Allirot et al., 2018) and mindful diaries (Hussein et al., 2017) to conventional mindfulness programmes (Raja-Khan et al., 2017), the field has been expanding and pilot and feasibility studies have become larger randomized clinical trials (e.g., Loucks et al., 2015; Mason et al., 2016) and population studies (Camilleri et al., 2015). Existing research has been useful in advancing understanding and practices around mindfulness, but in many ways, it appears as if we are taking a more informed and evidence-based path, which indeed, is depicted in this Research Topic of "mindfulness and eating behaviors."

\section{OVERVIEW OF CONTRIBUTIONS}

\section{OPEN ACCESS}

Edited and reviewed by: Alix Timko,

University of Pennsylvania, United States

${ }^{*}$ Correspondence: Michail Mantzios michael.mantzios@bcu.ac.uk

Specialty section:

This article was submitted to Eating Behavior, a section of the journal Frontiers in Psychology

Received: 15 August 2018 Accepted: 27 September 2018 Published: 12 October 2018

Citation:

Mantzios M (2018) Editorial: Mindfulness and Eating Behavior.

Front. Psychol. 9:1986 doi: 10.3389/fpsyg.2018.01986
The research topic opens with a manuscript by Tapper and Ahmed who present a controlled experiment around decentering, and investigate the mechanism of cognitively accessible goals to explain resistance to chocolate. When decentering was compared to a control group in assessing cognitive accessibility through the "word stem completion task," researchers found a significantly greater number of words relevant to health and weight loss in the decentering condition. The second manuscript by Masuda et al. reports a cross-sectional study investigating mindfulness as a moderating factor between eating disorder related cognitions and eating disorder behaviors across different ethnical backgrounds. While the moderation was true for the White American sample, mindfulness failed to moderate this relation between cognitions and behaviors for Asian and Black Americans. Findings suggest individual differences may influence the effectiveness of mindfulness practices, and propose future research with a greater emphasis on minority groups, as well as greater explorations of cross-cultural differences. The third manuscript (Soler et al.) compared findings across five groups (including four different clinical samples and a control group) on the experience of eating through a unique method of "direct experiential comprehension" of eating. Among the findings, importantly, healthy control and obesity patients scored higher on the "direct experience index" than the anorexia and bulimia samples. The findings suggest a close association between healthy control and obesity patients, meaning that there may be further considerations when we recommend elements surrounding mindful eating to obesity patients, or explorations of healthy populations enabling pilots that may be applicable to obesity samples. In the fourth manuscript, Brewer et al. put forward mechanisms for newer interventions that are relevant to habit formation, operant conditioning and intrinsic rewards. Discussions around intrinsic rewards have been long 
overdue in the field of mindfulness and eating, and may offer a potential variable in long-term adherence to both mindfulness and weight-regulation. Although personally I feel more inclined toward an approach that goes along with Brewer et al.'s model presented in this issue (e.g., see Mantzios and Giannou, 2018), the added elements of traditional contemplative practices (such as cultivating spiritual engagement) may propose a more indepth practice. In the fifth manuscript, Kristeller and Jordan do indeed tap into the additional value of spirituality within the mindfulness-based eating awareness training programme, and explore meaningful spiritual engagement as a benefit to the enhancement of self-regulatory processes. For novice participants and/or patients, it may be easier to start with secular practices (as seen in Soler et al.; Tapper and Ahmed) and build on them to create more sustainable practices (as in Brewer et al.). However, they may eventually transition onto non-secular practices, which may be deeper, and most likely, more effective and rewarding interventions, and this is definitely, what Kristeller and Jordan propose through their findings. Last, Egan and Mantzios, through a qualitative exploration, investigate perceptions of self-kindness and self-compassion, and draw associations between self-kindness and self-indulgence, while emphasizing an overarching theme of caring equally for body and mind (see Mantzios and Egan, 2017), which reflects on mindfulness practices and the way we need to perceive the non-evaluative and non-judgmental elements of engagement

\section{REFERENCES}

Allirot, X., Miragall, M., Perdices, I., Baños, R. M., Urdaneta, E., and Cebolla, A. (2018). Effects of a brief mindful eating induction on food choices and energy intake: external eating and mindfulness state as moderators. Mindfulness 9, 750-760. doi: 10.1007/s12671-017-0812-0

Camilleri, G. M., Méjean, C., Bellisle, F., Hercberg, S., and Péneau, S. (2015). Association between mindfulness and weight status in a general population from the NutriNet-Santé study. PLoS ONE 10:e0127447. doi: 10.1371/journal.pone.0127447

Hussein, M., Egan, H., and Mantzios, M. (2017). Mindful construal diaries: a less anxious, more mindful, and more self-compassionate method of eating. Sage Open 7, 1-8. doi: 10.1177/2158244017704685

Kristeller, J. L., and Hallett, C. B. (1999). An exploratory study of a meditationbased intervention for binge eating disorder. J. Health Psychol. 4, 357-363. doi: $10.1177 / 135910539900400305$

Kristeller, J. L., and Wolever, R. Q. (2010). Mindfulness-based eating awareness training for treating binge eating disorder: the conceptual foundation. Eat. Disord. 19, 49-61. doi: 10.1080/10640266.2011.533605

Loucks, E. B., Britton, W. B., Howe, C. J., Eaton, C. B., and Buka, S. L. (2015). Positive associations of dispositional mindfulness with cardiovascular health: the New England Family Study. Int. J. Behav. Med. 22, 540-550. doi: 10.1007/s12529-014-9448-9

Mantzios, M., and Egan, H. H. (2017). On the role of self-compassion and selfkindness in weight regulation and health behavior change. Front. Psychol. 8:229. doi: 10.3389/fpsyg.2017.00229

Mantzios, M., and Giannou, K. (2018). A real-world application of short mindfulness-based practices: a review and reflection of the literature and a with food. The descriptions of the manuscripts presented in this editorial are by no means inclusive of the full content, but more likely an invitation to read and comment on the methods and findings of the manuscripts further. Throughout the Research Topic, the authors engage in discussions and offer deeply insightful comments on the findings, as well as inspiring projections for future research.

Indeed, the collection of work proposes exceptionally well-executed experiments, in-depth qualitative explorations, examinations of the role of ethnical background and spirituality in mindfulness and mindfulness programmes, and different theoretical directions. Jointly, the manuscripts put forward stimulating directions for future cross-sectional, experimental and longitudinal research in mindfulness and eating behaviors. Looking forward and at the wider range of investigation, there may be a need for a consensus manuscript that puts forward standardized practices and methods that can be used easily and freely, to compare findings and replicate significant and influential research in the field. Together we may be able to make a difference, and together we may be able to change the impact of mindfulness on the quality, quantity and the ways that we eat.

\section{AUTHOR CONTRIBUTIONS}

The author confirms being the sole contributor of this work and has approved it for publication. practical proposition for an effortless mindful lifestyle. Am. J. Lifestyle Med. doi: $10.1177 / 1559827618772036$. [Epub ahead of print].

Mantzios, M., and Wilson, J. C. (2015). Mindfulness, eating behaviours, and obesity: a review and reflection on current findings. Curr. Obes. Rep. 4, 141-146. doi: 10.1007/s13679-014-0131-x

Mason, A. E., Epel, E. S., Aschbacher, K., Lustig, R. H., Acree, M., Kristeller, J., et al. (2016). Reduced reward-driven eating accounts for the impact of a mindfulness-based diet and exercise intervention on weight loss: data from the SHINE randomized controlled trial. Appetite 100, 86-93. doi: 10.1016/j.appet.2016.02.009

Raja-Khan, N., Agito, K., Shah, J., Stetter, C. M., Gustafson, T. S., Socolow, H., et al. (2017). Mindfulness-based stress reduction in women with overweight or obesity: a randomized clinical trial. Obesity 25, 1349-1359. doi: 10.1002/oby.21910

Tapper, K. (2017). Can mindfulness influence weight management related eating behaviors? If so, how? Clin. Psychol. Rev. 53, 122-134. doi: $10.1016 /$ j.cpr.2017.03.003

Conflict of Interest Statement: The author declares that the research was conducted in the absence of any commercial or financial relationships that could be construed as a potential conflict of interest.

Copyright () 2018 Mantzios. This is an open-access article distributed under the terms of the Creative Commons Attribution License (CC BY). The use, distribution or reproduction in other forums is permitted, provided the original author(s) and the copyright owner(s) are credited and that the original publication in this journal is cited, in accordance with accepted academic practice. No use, distribution or reproduction is permitted which does not comply with these terms. 